\title{
Interventions are needed to support patient-provider decision-making for DCIS: a scoping review
}

\author{
Claire $\mathrm{Kim}^{1} \cdot$ Laurel Liang ${ }^{1} \cdot$ Frances C. Wright ${ }^{2} \cdot$ Nicole J. Look Hong ${ }^{2} \cdot$ Gary Groot $^{3} \cdot$ Lucy Helyer $^{4} \cdot$ Pamela Meiers $^{3}$. \\ May Lynn Quan ${ }^{5} \cdot$ Robin Urquhart $^{4} \cdot$ Rebecca Warburton $^{6} \cdot$ Anna R. Gagliardi $^{1}$ (i)
}

Received: 14 September 2017 / Accepted: 6 December 2017 / Published online: 23 December 2017

(c) The Author(s) 2017. This article is an open access publication

\begin{abstract}
Purpose Prognostic and treatment uncertainty make ductal carcinoma in situ (DCIS) complex to manage. The purpose of this study was to describe research that evaluated DCIS communication experiences, needs and interventions among DCIS patients or physicians.

Methods MEDLINE, EMBASE, CINAHL and The Cochrane Library were searched from inception to February 2017. English language studies that evaluated patient or physician DCIS needs, experiences or behavioural interventions were eligible. Screening and data extraction were done in duplicate. Summary statistics were used to describe study characteristics and findings.

Results A total of 51 studies published from 1997 to 2016 were eligible for review, with a peak of 8 articles in year 2010. Women with DCIS lacked knowledge about the condition and its prognosis, although care partners were more informed, desired more information and experienced decisional conflict. Many chose mastectomy or prophylactic mastectomy, often based on physician's recommendation. Following treatment, women had anxiety and depression, often at levels similar to those with invasive breast cancer. Disparities were identified by education level, socioeconomic status, ethnicity and literacy. Physicians said that they had difficulty explaining DCIS and many referred to DCIS as cancer. Despite the challenges reported by patients and physicians, only two studies developed interventions designed to improve patient-physician discussion and decision-making.

Conclusions As most women with DCIS undergo extensive treatment, and many experience treatment-related complications, the paucity of research on PE to improve and support informed decision-making for DCIS is profound. Research is needed to improve patient and provider discussions and decision-making for DCIS management.
\end{abstract}

Keywords Ductal carcinoma in situ $\cdot$ Communication $\cdot$ Decision-making $\cdot$ Supportive care

\section{Abbreviations}

DCIS Ductal carcinoma in situ

\section{Background}

Approximately $15-25 \%$ of mammographically detected lesions are ductal carcinoma in situ (DCIS), an unintended consequence of screening mammography [1]. DCIS is a

Electronic supplementary material The online version of this article (https://doi.org/10.1007/s10549-017-4613-x) contains supplementary material, which is available to authorized users.

Anna R. Gagliardi

anna.gagliardi@uhnresearch.ca

Extended author information available on the last page of the article complex premalignant disease that includes a spectrum of abnormal cell types confined to the breast ducts with variable natural history and risk of progression and recurrence [1]. Approximately $20 \%$ of cases will progress to invasive ductal carcinoma so most women with DCIS will never develop invasive disease and have a favourable prognosis $[1,2]$. The 20 -year breast cancer-specific mortality is $3.3 \%$ (95\% CI 3.0-3.6) [2]. Currently, there is no reliable way to determine which women with DCIS will develop invasive disease, although strategies for determining recurrence risk based on pathologic indicators are forthcoming [1]. DCIS may be more aggressive in women under the age of $50 \mathrm{com}$ pared with postmenopausal women [2]. However, until evidence emerges from ongoing trials [3] and guidelines are updated [4], it is not possible to triage women who may be able to achieve good oncologic outcomes with less invasive 
treatment. Consequently, as recommended by guidelines, most women undergo lumpectomy-alone, lumpectomy and adjuvant radiation and/or hormone therapy, or mastectomy, and may experience short- and long-term treatment-related complications $[4,5]$.

Women diagnosed with DCIS reported confusion about DCIS, treatment options (lumpectomy versus mastectomy, need for radiation therapy) along with possible complications, and their prognosis and, as a result, had poor health care experiences and adverse health outcomes [6-10]. Physicians also reported challenges in communicating with patients about DCIS: $22 \%$ of 296 physicians in the United Kingdom and $78 \%$ of 151 physicians in the United States said that it was difficult to explain DCIS and treatment options to patients [7, 8]. Patient engagement is defined as care that informs, educates, engages and activates patients consistent with their needs and values [11]. Research shows that patient engagement improves patient knowledge, relationship with providers, service experience and satisfaction, treatment compliance, health outcomes and cost-effective service delivery and use [12-14]. A Cochrane review showed that PE is more probable if strategies to support it are aimed not only at patients, but also at physicians who influence treatment choices [15].

Prognostic uncertainty and treatment options with associated potential complications make DCIS unique from, and more challenging than, management of invasive breast cancer for both patients and providers, resulting in detrimental experiences and outcomes for patients. PE is relevant in circumstances where there is limited evidence to support decision-making; two or more treatment options are suitable; or treatment outcomes are difficult to predict, or may be adverse, as is the case for DCIS [16]. Both patients and providers would benefit from interventions or tools such as education or decision aids that support patient engagement for DCIS. First, thorough insight is needed on DCIS communication experiences and interventions among patients and physicians. This would identify whether sufficient knowledge exists, or further research is needed to understand DCIS communication experiences and develop corresponding interventions. The purpose of this study was to describe the characteristics and findings of existing research that evaluated DCIS communication experiences, needs and interventions among patients or physicians.

\section{Methods}

\section{Approach}

A scoping review was chosen as the methodologic approach $[14,17,18]$. Similar in rigour to a traditional systematic review, the purpose of a scoping review is to gain an understanding of the extent of research on a given topic, reveal gaps in knowledge and identify issues warranting ongoing research [19]. A scoping review involves five steps: scoping the literature, searching, screening, data extraction and data analysis. The Preferred Reporting Items for Systematic Reviews and Meta-Analyses [20] criteria guided reporting of the methods and findings [14]. Data were publicly available so institutional review board approval was not needed. A protocol for this review was not registered.

\section{Scoping}

The scoping process involved becoming familiar with the literature on this topic using few high-level search terms so as not to eliminate any relevant concepts. A preliminary search was conducted in MEDLINE using Medical Subject Headings including, but not limited to, (ductal carcinoma in situ) and (patient education as topic or patient-centered care). CK and ARG screened titles and abstracts of the preliminary search results, which were used to plan a more comprehensive search strategy and to generate eligibility criteria based on the PICO (population, intervention, comparisons, outcomes) framework. The PICO framework is commonly used in systematic reviews to thoroughly address all relevant eligibility criteria such that subsequent searching and screening are optimized. All members of the research team, composed of health services researchers and general surgeons who care for cancer patients, reviewed eligibility criteria and provided feedback.

Populations referred to both patients and health care professionals. Patients included those diagnosed with DCIS. Health care professionals were practising physicians who manage patients with DCIS including general surgeons, and surgical, radiation and medical oncologists because they are the individuals who discuss diagnosis and treatment options with patients. Interventions included any policy, programme or single- or multi-faceted strategy implemented to promote awareness, understanding and discussion about DCIS. With respect to comparisons, studies were eligible if they explored or evaluated the following aspects of DCIS: understanding of the disease; views about the disease; communication about the disease; experiences and psychosocial outcomes of undergoing treatment for DCIS; determinants or factors influencing DCIS understanding, views, communication, experiences or choice; or behavioural interventions to support or improve any of these functions by comparing patients or providers with and without exposure to interventions, or before or after exposure to interventions, or receiving different types of interventions. Outcomes were those reported in eligible studies and included but were not limited to awareness, understanding, communication, experiences or impacts of DCIS, or determinants or factors influencing any of these functions, or the impact of behavioural interventions 
Table 1 Search strategy

\begin{tabular}{|c|c|c|}
\hline \# & Searches & Results \\
\hline 1 & Carcinoma, Intraductal, Noninfiltrating/ & 8623 \\
\hline 2 & $\begin{array}{l}\text { CARCINOMA, DUCTAL/ [used 1963-93, use CARCINOMA, INTRADUCTAL, NONINFILTRATING to search CARCI- } \\
\text { NOMA, DUCTAL 1966-93] }\end{array}$ & 1187 \\
\hline 3 & limit 2 to $y r=" 1902-1965 "$ & 124 \\
\hline 4 & dcis.mp. & 3612 \\
\hline 5 & ductal carcinoma* in situ.mp. & 5237 \\
\hline 6 & (carcinoma* adj4 intraductal).mp. & 9543 \\
\hline 7 & Paget's Disease, Mammary/ & 698 \\
\hline 8 & 1 or 3 or 4 or 5 or 6 or 7 & 13041 \\
\hline 9 & Patient Education as Topic/ & 77452 \\
\hline 10 & patient education handout/ & 4531 \\
\hline 11 & (patient* adj4 educat*).mp. & 100404 \\
\hline 12 & Comprehension/ & 10834 \\
\hline 13 & (readable or readability).mp. & 2895 \\
\hline 14 & exp Learning/ & 328881 \\
\hline 15 & (patient* adj4 learn*).mp. & 5677 \\
\hline 16 & (patient* adj4 know*).mp. & 39386 \\
\hline 17 & (patient* adj4 understand*).mp. & 14038 \\
\hline 18 & (patient* adj4 (comprehend* or comprehension*)).mp. & 950 \\
\hline 19 & exp Informed Consent/ & 38029 \\
\hline 20 & informed.mp. & 87866 \\
\hline 21 & (patient* adj4 communicat*).mp. & 16285 \\
\hline 22 & exp Communications Media/ & 273700 \\
\hline 23 & (information adj4 needs).mp. & 5233 \\
\hline 24 & (information adj4 obtain*).mp. & 42149 \\
\hline 25 & ((apply or applie? or applying or application?) adj4 information).mp. & 5881 \\
\hline 26 & (patient* adj4 (explain??? or explanation?)).mp. & 7471 \\
\hline 27 & (educat* adj4 (barrier* or facilitat*)).mp. & 2810 \\
\hline 28 & (learn* adj4 (barrier* or facilitat* or challeng*)).mp. & 5599 \\
\hline 29 & (know* adj4 (barrier* or facilitat* or challeng*)).mp. & 6047 \\
\hline 30 & (understand* adj4 (barrier* or facilitat* or challeng*)).mp. & 10614 \\
\hline 31 & $(($ comprehend* or comprehension*) adj4 (barrier* or facilitat* or challeng*)).mp. & 354 \\
\hline 32 & (communicat* adj4 (barrier* or facilitat* or challeng*)).mp. & 10641 \\
\hline 33 & (information adj4 (barrier* or facilitat* or challeng*)).mp. & 5390 \\
\hline 34 & ((knowledge or information) adj4 access*).mp. & 15943 \\
\hline 35 & ((knowledge or information) adj4 broker*).mp. & 199 \\
\hline 36 & $(($ knowledge or information) adj4 spread*).mp. & 1128 \\
\hline 37 & ((knowledge or information) adj4 flow???).mp. & 5329 \\
\hline 38 & ((knowledge or information) adj4 collect*).mp. & 23574 \\
\hline 39 & (translat* adj4 (information or knowledge)).mp. & 4584 \\
\hline 40 & ((knowledge or information) adj4 exchang*).mp. & 6091 \\
\hline 41 & ((information or knowledge) adj4 (acquisition or acquir*)).mp. & 10596 \\
\hline 42 & ((information or knowledge) adj4 gain???).mp. & 13039 \\
\hline 43 & exp Communication/ [includes communication barriers, health communication etc.] & 420493 \\
\hline 44 & misunderstand*.mp. & 3836 \\
\hline 45 & miscommunicat*.mp. & 489 \\
\hline 46 & mistaught.mp. & 1 \\
\hline 47 & misinform*.mp. & 1905 \\
\hline 48 & $($ communicat* adj4 (fail* or error*)).mp. & 1408 \\
\hline 49 & (understand* adj4 (fail* or error*)).mp. & 1986 \\
\hline
\end{tabular}


Table 1 (continued)

\begin{tabular}{|c|c|c|}
\hline \# & Searches & Results \\
\hline 50 & misunderstood.mp. & 1737 \\
\hline 51 & (incomprehend* or incomprehension*).mp. & 48 \\
\hline 52 & confus???.mp. & 43867 \\
\hline 53 & uninform*.mp. & 2047 \\
\hline 54 & (knowledge* adj4 (fail* or error*)).mp. & 1165 \\
\hline 55 & (information* adj4 (fail* or error*)).mp. & 2531 \\
\hline 56 & ((knowledge or information) adj4 lack???).mp. & 21650 \\
\hline 57 & (communicat* adj4 lack???).mp. & 1521 \\
\hline 58 & (understand* adj4 lack???).mp. & 4506 \\
\hline 59 & ((explanation* or explain*) adj4 lack???).mp. & 4180 \\
\hline 60 & ((teach* or taught) adj4 lack???).mp. & 403 \\
\hline 61 & (educat* adj4 lack???).mp. & 2559 \\
\hline 62 & (knowledge adj4 gap?).mp. & 9651 \\
\hline 63 & (information adj4 gap?).mp. & 1323 \\
\hline 64 & (communication adj4 gap?).mp. & 3720 \\
\hline 65 & (understanding adj4 gap?).mp. & 2150 \\
\hline 66 & (understanding adj4 gain???).mp. & 10192 \\
\hline 67 & (knowledge adj4 (inaccura* or incomplete* or incorrect*)).mp. & 1046 \\
\hline 68 & (information adj4 (inaccura* or incomplete* or incorrect*)).mp. & 2399 \\
\hline 69 & $(($ explanation* or explain*) adj4 (inaccura* or incomplete* or incorrect*)).mp. & 586 \\
\hline 70 & $(($ teach* or taught) adj4 (inaccura* or incomplete* or incorrect*)).mp. & 56 \\
\hline 71 & (communicat* adj4 (inaccura* or incomplete* or incorrect*)).mp. & 112 \\
\hline 72 & (understand* adj4 (inaccura* or incomplete* or incorrect*)).mp. & 1382 \\
\hline 73 & $(($ teach* or taught $)$ adj4 (barrier* or facilitat*)).mp. & 935 \\
\hline 74 & (patient* adj4 (teach* or taught)).mp. & 6701 \\
\hline 75 & (learn* adj4 (fail* or error* or lack??? or gap? or incomplete* or inaccura* or incorrect*)).mp. & 3492 \\
\hline 76 & exp Patient Satisfaction/ & 73809 \\
\hline 77 & (patient* adj4 satisf*).mp. & 97266 \\
\hline 78 & (patient* adj4 experienc*).mp. & 106283 \\
\hline 79 & (patient* adj4 prefer*).mp. & 23059 \\
\hline 80 & “illness experience?”.mp. & 1134 \\
\hline 81 & “diagnos* experience?”.mp. & 307 \\
\hline 82 & “prognos* experience?”.mp. & 14 \\
\hline 83 & “treatment* experience?”.mp. & 2765 \\
\hline 84 & “follow-up experience?”.mp. & 182 \\
\hline 85 & “survivorship experience?”.mp. & 57 \\
\hline 86 & “experience of illness”.mp. & 491 \\
\hline 87 & “experience of diagnos*”.mp. & 928 \\
\hline 88 & “experience of prognos*”.mp. & 68 \\
\hline 89 & “experience of treatment*".mp. & 1967 \\
\hline 90 & “experience of follow-up”.mp. & 177 \\
\hline 91 & “experience of survivorship".mp. & 12 \\
\hline 92 & CONSUMER SATISFACTION/ [use to search PATIENT SATISFACTION 1982-91] & 19040 \\
\hline 93 & exp Public Relations/ & 109728 \\
\hline 94 & (positive adj4 experience*).mp. & 6949 \\
\hline 95 & (negative adj4 experience*).mp. & 5360 \\
\hline 96 & (good adj4 experience*).mp. & 2073 \\
\hline 97 & (bad adj4 experience*).mp. & 338 \\
\hline 98 & (respect* adj4 interact*).mp. & 4643 \\
\hline 99 & $($ respect* adj4 treat*).mp. & 33437 \\
\hline
\end{tabular}


Table 1 (continued)

\begin{tabular}{|c|c|c|}
\hline \# & Searches & Results \\
\hline 100 & (respect* adj4 conversat*).mp. & 42 \\
\hline 101 & disrespect*.mp. & 505 \\
\hline 102 & (good adj4 communicat*).mp. & 1988 \\
\hline 103 & (poor adj4 communicat*).mp. & 1576 \\
\hline 104 & (respect* adj4 communicat*).mp. & 730 \\
\hline 105 & (shar* adj4 decision).mp. & 4117 \\
\hline 106 & (enough adj4 information*).mp. & 1736 \\
\hline 107 & (enough adj4 communicat*).mp. & 63 \\
\hline 108 & (sufficien* adj4 information*).mp. & 4632 \\
\hline 109 & (sufficien* adj4 communicat*).mp. & 187 \\
\hline 110 & (insufficien* adj4 information*).mp. & 2211 \\
\hline 111 & (insufficien* adj4 communicat*).mp. & 238 \\
\hline 112 & listening.mp. & 12362 \\
\hline 113 & Decision Making/ & 79019 \\
\hline 114 & exp Choice Behavior/ & 46792 \\
\hline 115 & (decision* or decide* or deciding).mp. & 344149 \\
\hline 116 & (choice* or choose* or chose*).mp. & 375015 \\
\hline 117 & exp patient centered care/ & 14724 \\
\hline 118 & (patient* adj2 (centered or centred)).mp. & 21245 \\
\hline 119 & exp Professional-Patient Relations/ & 130244 \\
\hline 120 & (relations* adj4 (physician* or doctor* or professional*) adj4 patient*).mp. & 102931 \\
\hline 121 & health literacy/ & 3159 \\
\hline 122 & health literac*.mp. & 4914 \\
\hline 123 & health literate.mp. & 89 \\
\hline 124 & exp Attitude to Health/ & 349676 \\
\hline 125 & (health adj4 (knowledg* or attitude*)).mp. & 255723 \\
\hline 126 & Practice Patterns, Physicians'/ & 48762 \\
\hline 127 & practice pattern*.mp. & 55115 \\
\hline 128 & pattern* of practice.mp. & 485 \\
\hline 129 & Professional Practice/ & 16018 \\
\hline 130 & exp Consumer Participation/ & 36274 \\
\hline 131 & (participat* adj4 (patient* or consumer* or client*)).mp. & 42306 \\
\hline 132 & decision support techniques/ & 15967 \\
\hline 133 & Decision Support Systems, Clinical/ & 6197 \\
\hline 134 & Patient Care Management/ & 2811 \\
\hline 135 & exp Patient Care Planning/ & 58229 \\
\hline 136 & disease management/ & 26772 \\
\hline 137 & (care adj2 (manag* or plan*)).mp. & 89775 \\
\hline 138 & "Quality of Health Care"/ & 64024 \\
\hline 139 & Quality Improvement/ & 12994 \\
\hline 140 & exp Quality Assurance, Health Care/ & 288987 \\
\hline 141 & (quality adj4 care).mp. & 157694 \\
\hline 142 & (quality adj4 improv*).mp. & 110356 \\
\hline 143 & (quality adj4 (high or low)).mp. & 57255 \\
\hline 144 & (quality adj4 increas*).mp. & 12900 \\
\hline 145 & (quality adj4 (good or poor or bad)).mp. & 28967 \\
\hline 146 & (quality adj4 (better or worse*)).mp. & 13421 \\
\hline 147 & (quality adj4 (assur* or ensur*)).mp. & 70255 \\
\hline 148 & or/9-147 & 2984559 \\
\hline 149 & 8 and 148 & 1611 \\
\hline
\end{tabular}


Table 1 (continued)

\begin{tabular}{|c|c|c|}
\hline \# & Searches & Results \\
\hline 150 & remove duplicates from 149 & 1567 \\
\hline 151 & exp animals/ not (exp animals/ and exp humans/) & 4319036 \\
\hline 152 & 150 not 151 & 1562 \\
\hline 153 & $\begin{array}{l}\text { limit } 152 \text { to ("all adult (19 plus years)" or "young adult (19 to } 24 \text { years)" or "adult (19 to } 44 \text { years)" or "young adult and adult } \\
\text { (19-24 and 19-44)" or "middle age ( } 45 \text { to } 64 \text { years)" or "middle aged ( } 45 \text { plus years)" or "all aged ( } 65 \text { and over)" or "aged ( } 80 \\
\text { and over)") }\end{array}$ & 1031 \\
\hline 154 & $\begin{array}{l}\text { limit } 152 \text { to ("all infant (birth to } 23 \text { months)" or "all child (0 to } 18 \text { years)" or "newborn infant (birth to } 1 \text { month)" or "infant (1 } \\
\text { to } 23 \text { months)" or "preschool child ( } 2 \text { to } 5 \text { years)" or "child (6 to } 12 \text { years)" or "adolescent (13 to } 18 \text { years)") }\end{array}$ & 54 \\
\hline 155 & 152 not 154 & 1508 \\
\hline 156 & 153 or 155 & 1559 \\
\hline 157 & limit 156 to female & 1458 \\
\hline 158 & (wom\#n or female?).mp. & 7645637 \\
\hline 159 & 156 and 158 & 1469 \\
\hline 160 & 157 or 159 & 1469 \\
\hline 161 & limit 160 to english language & 1343 \\
\hline 162 & 160 not 161 & 126 \\
\hline
\end{tabular}

implemented to support or improve any of these functions. Eligible study designs included English language qualitative (interviews, focus groups, qualitative case studies), quantitative (questionnaires, randomized controlled trials, time series, before/after studies, prospective or retrospective cohort studies, case-control studies) or mixed methods studies. Systematic reviews were not eligible, but their references and those of all eligible studies were screened to identify additional eligible primary studies.

\section{Searching}

The search strategy was developed in conjunction with a medical librarian and complied with the Peer Review of Electronic Search Strategy reporting guidelines (Table 1) [21]. MEDLINE, EMBASE, CINAHL, and the Cochrane Library were searched on February 16, 2017 from inception to that date.

\section{Screening}

To prepare for screening, CK and ARG independently screened the title and abstract of the first 25 search results, then compared and discussed discrepancies and how to interpret and apply the eligibility criteria. CK, LL and ARG screened titles and abstracts according to specified PICObased eligibility criteria. Criteria for ineligible studies were generated prospectively with screening. Studies were not eligible if they primarily involved health care providers other than practising physicians who discuss diagnosis and treatment with patients (nurses or allied health care professionals including but not limited to physiotherapists, speech therapists, occupational therapists, social workers, pharmacists; or trainee physicians such as interns, residents or fellows; studies were included if at least half the participants were practising physicians); examined the clinical effectiveness of DCIS treatment options; or were in the form of protocols, editorials, commentaries, letters, news items, meeting abstracts or proceedings. All items selected by at least one reviewer were retrieved.

\section{Data extraction}

A data extraction form was developed to collect information on study characteristics including author, publication year, country, study objective, research design, participants and findings. If an intervention was employed, data were also extracted on content (information/knowledge conveyed), format (mode of delivery, single- or multi-faceted), timing (duration, frequency), participants (number, type, setting) and personnel who delivered the intervention according to the Workgroup for Intervention Development and Evaluation Research [22] reporting standards for behavioural interventions [14, 17, 18]. To pilot data extraction, CK, LL and ARG independently extracted data from the same three articles, and compared and discussed findings to refine the data extraction form. CK and LL extracted data from all articles, which were independently checked by ARG.

\section{Data analysis}

Summary statistics were used to report the number of studies published per year, by type of cancer, in different countries and according to study design. Study findings were reported 
narratively. Methodological quality of included studies was not assessed as this is not customary for a scoping review.

\section{Results}

\section{Search results}

A total of 3753 studies were identified by searches, of which 3442 were unique items, and 3195 were excluded based on screening of titles and abstracts. Among 247 full-text articles that were screened, 206 were excluded because they focused on effectiveness of clinical treatment (99), studies did not match DCIS eligibility criteria (85), the publication type was not eligible (21), or duplicate (1). Of 27 systematic reviews identified through screening, two were relevant and 10 additional eligible primary studies were identified among their references. A total of 51 studies were eligible for review (Fig. 1). Data extracted from included studies are available in Table 2 and discussed here [23-73]. Themes that emerged from the included studies are summarized in Table 2.

\section{Study characteristics}

The number of studies generally increased from 1997 to 2016, peaking at 8 articles in year 2010 (Fig. 2). Studies were conducted in the United States (28), United Kingdom (9), Australia (6), Canada (3), Italy (1), Netherlands (1), Sweden (1), Switzerland (1) and Tasmania (1). With respect to research design, most studies involved cross-sectional questionnaires $(21,41.2 \%)$, followed by qualitative interviews or focus groups $(19,37.3 \%)$, single cohorts $(4,7.8 \%)$, mixed methods $(5,9.8 \%)$ and comparative cohorts $(2,3.9 \%)$.

\section{Knowledge about DCIS and prognosis $(n=14$ studies)}

Four studies found that none or few women had heard of DCIS prior to diagnosis [41, 46, 57, 63]. Another four studies found that women with DCIS were unsure of whether or not their disease was invasive $[41,42,63,73]$. Several studies found that women overestimated their risk from DCIS [49] and worry about dying from breast disease was significantly associated with thinking that DCIS could metastasize [42]. A study of 181 women with DCIS found that participants perceived a moderate risk of DCIS spreading in the body (24\%), developing DCIS again within 5 years (32\%), developing DCIS again within their lifetime (43\%), developing invasive breast cancer within 5 years $(27 \%)$ and developing invasive cancer within their lifetime (38\%) [36]. Women who were financially comfortable or at least college graduates were less likely to perceive that DCIS could spread, or that the risk of DCIS was moderate or large [36]. Fifteen percent of DCIS patients in one study reported their recurrence risk to be $>50 \%$ [50]. Another study found that, although $41.0 \%$ of DCIS patients were aware that their disease was not life threatening, $15.0 \%$ of patients reported their recurrence risk to be greater than 50.0\% [35]. Englishspeaking whites were more likely to know that DCIS is not life-threatening compared with Latina women (OR 95\%

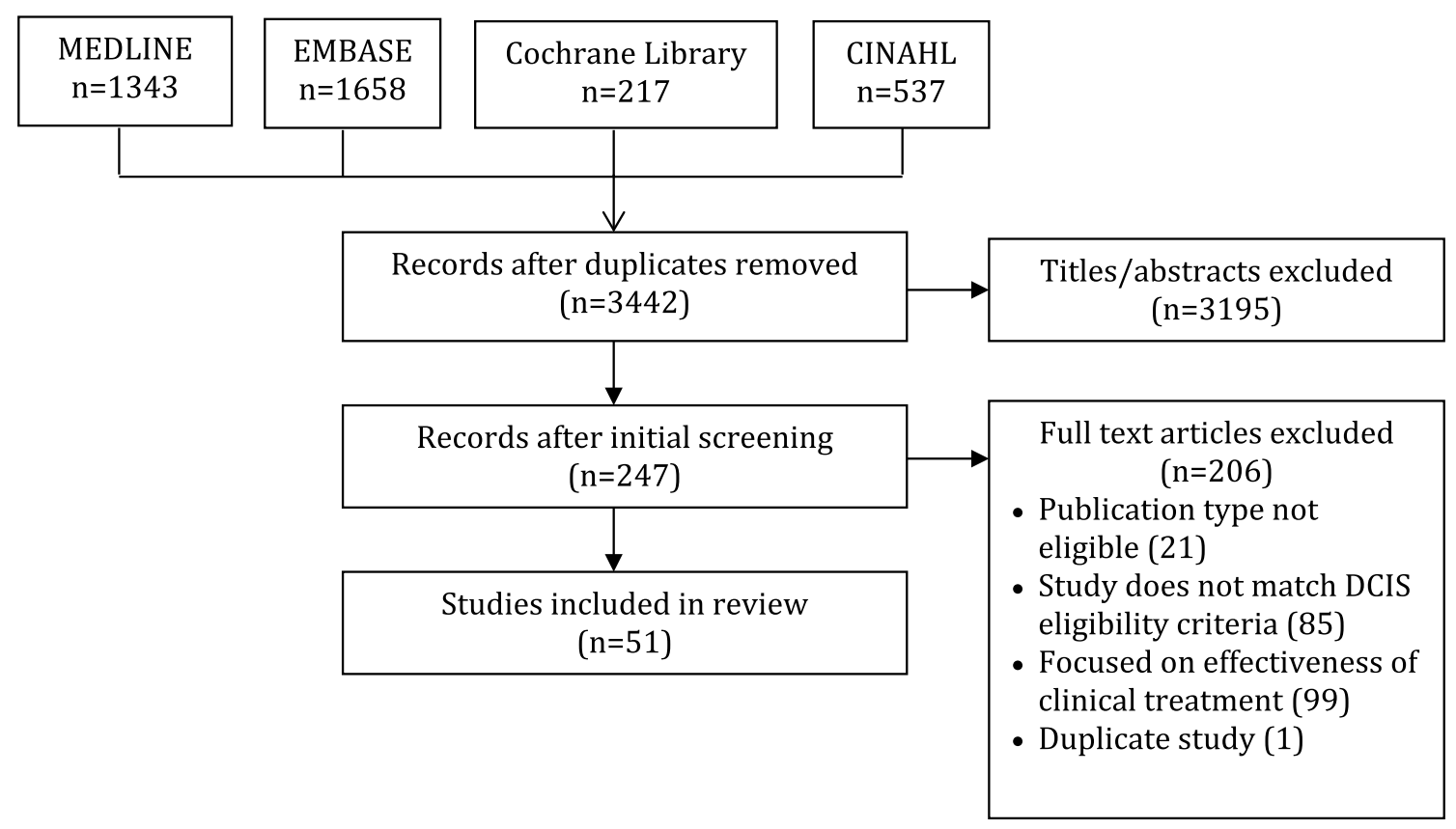

Fig. 1 PRISMA diagram 
Table 2 Themes that emerged from included studies

\begin{tabular}{|c|c|c|}
\hline Domain ( $n$ studies) & Themes & Studies \\
\hline \multirow[t]{4}{*}{ Knowledge about DCIS and its prognosis [14] } & Little awareness or knowledge about DCIS & {$[23,41,46,57,63]$} \\
\hline & Failure to distinguish DCIS from invasive breast cancer & {$[41,42,45,63,64,66,73]$} \\
\hline & Inaccurate perception of risk for invasiveness/recurrence & {$[35,36,49,50]$} \\
\hline & Influenced by socioeconomic status, race & {$[35,36]$} \\
\hline \multirow[t]{7}{*}{ Communication and decision-making [28] } & $\begin{array}{l}\text { Sources of information (in no particular order): surgeons, breast } \\
\text { cancer nurses, Internet, books, leaflets, medical journals, } \\
\text { cancer charities }\end{array}$ & {$[58,63,71]$} \\
\hline & Not satisfied with information about DCIS provided to them & {$[70,72]$} \\
\hline & High level of decisional conflict & {$[42,46,59]$} \\
\hline & $\begin{array}{l}\text { Decisions highly influenced by physician recommendation, } \\
\text { patient age, race, patient concern about recurrence }\end{array}$ & $\begin{array}{l}{[24,25,28,30,33,37,38,44} \\
\quad 55,60,65,68]\end{array}$ \\
\hline & $\begin{array}{l}\text { Informed or shared decision-making influenced by socioeco- } \\
\text { nomic status }\end{array}$ & {$[30,33,38,44]$} \\
\hline & $\begin{array}{l}\text { Challenges faced by physicians were uncertainty about appro- } \\
\text { priate treatment and explaining DCIS to patients }\end{array}$ & {$[54,56]$} \\
\hline & $\begin{array}{l}\text { Physicians referred to DCIS as abnormal cells, early form of } \\
\text { cancer, cancer, cancerous or malignant cells and non-invasive } \\
\text { cancer }\end{array}$ & {$[25,26,29,39,42,56,58,67]$} \\
\hline \multirow[t]{4}{*}{ Psychosocial impact of DCIS [19] } & $\begin{array}{l}\text { Range of emotions from calm acceptance and relief that disease } \\
\text { caught early through to shock and distress }\end{array}$ & {$[39,46,47,52,73]$} \\
\hline & $\begin{array}{l}\text { Following treatment women experienced worsened body image, } \\
\text { lower quality of life, poor relationships with others, decreased } \\
\text { sexual desire or activity, tension, anxiety, loneliness and } \\
\text { depression }\end{array}$ & {$[31,48,52,58,62,70,72]$} \\
\hline & $\begin{array}{l}\text { Some women reported high degree of social support, little } \\
\text { impact on sexual function or quality of life, or little strain on } \\
\text { interpersonal relationships compared with women who had } \\
\text { invasive breast cancer }\end{array}$ & {$[31,34,40,51,53,58,64,66]$} \\
\hline & Influenced by socioeconomic status, no partner and age & {$[32]$} \\
\hline $\begin{array}{l}\text { Interventions to support DCIS communica- } \\
\text { tion or decision-making [2] }\end{array}$ & $\begin{array}{l}\text { Women with DCIS and physician thought that communication } \\
\text { or decisions aids would help patients understand DCIS, and its } \\
\text { treatment and prognosis }\end{array}$ & {$[27,43]$} \\
\hline
\end{tabular}

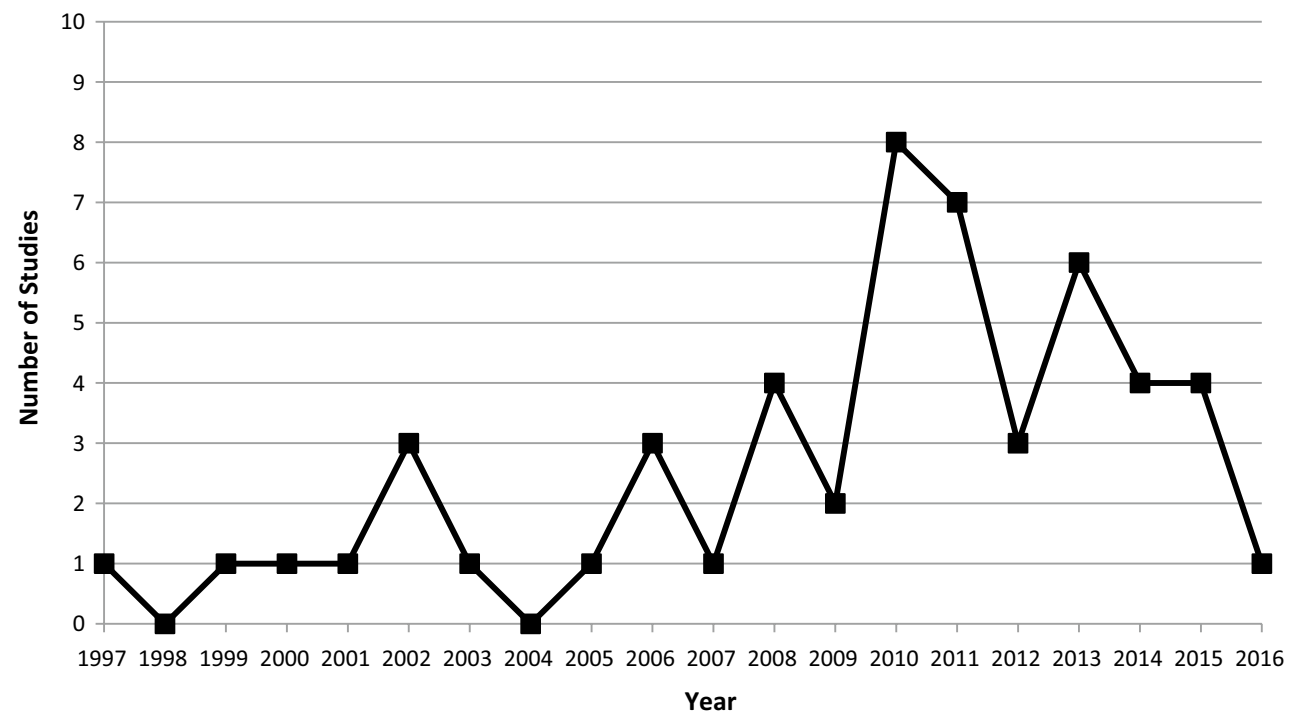

Fig. 2 Studies published per year 
CI 90.6, 0.4-0.9 and 0.5, 0.3-0.9, respectively) [35]. Two studies found that partners of patients were more likely to know about risk of recurrence compared with the patients ( $p=0.003$ ) [23]. Three studies found that DCIS and invasive breast cancer patients had comparable risk perceptions concerning the risk of recurrence $[45,64,66]$, and two studies found similar risk perceptions of dying of their disease $[64,66]$.

\section{Communication and decision-making $(n=28$ studies)}

Women reported that surgeons $[58,71]$ and breast cancer nurses [39] were important providers of information about DCIS. Two studies found that patients were not satisfied with the information they received about DCIS [70, 72]. Women acquired information from various sources including the Internet $[63,71]$, books, leaflets, medical journals, cancer charities, and health professionals [63]. Three studies found that women diagnosed with DCIS expressed high decisional conflict regarding treatment choice [42, 46, 59]. Patients said that their surgeon discussed both mastectomy and breast-conserving surgery, and those who chose mastectomy were influenced by concern of recurrence [65]. In an American study comparing Whites to Latinas, discussion of therapy or treatment decisions was less likely with Spanish-speaking Latinas. This group was also less affluent, less educated, had lower rates of employment, and were less likely to be privately insured [38] or report making decisions together with their physicians [30, 33, 44]. A study of treatment decision-making among Chinese-Canadian women found that they wanted to get rid of breast cancer once and for all and were influenced by physician recommendations [60]. Patients with DCIS who opted for mastectomy were more likely to be younger and have higher grade tumours $[25,37,44]$ compared with those undergoing breast-conserving surgery. One study found that younger age was associated with mastectomy [44, 65], while another found that breast-conserving surgery was more likely among younger patients [68]. Those who chose contralateral prophylactic mastectomy were younger or married [24, 28, 55], or white race or having the presence of lobular carcinoma in situ [55].

According to healthcare professionals, the most common challenge for DCIS patients was "understanding the condition" [56]. Physicians said that the greatest challenge they faced pertained to uncertainty about appropriate treatment [54]. One study found that $51.4 \%$ of the health care professionals surveyed found DCIS more difficult to explain to patients than invasive cancer (only $9 \%$ found DCIS easier to explain) [56]. DCIS was described by physicians using a variety of terms including abnormal cells $[26,56]$, precancer or pre-invasive breast cancer cells [25, 26, 39, 56], abnormal cells in the milk ducts [67], earliest possible form of breast cancer [39], not breast cancer as we commonly think of breast cancer [42], cancer, cancerous cells, malignant cells, changes [56], and non-invasive cancer [58]. One study found that physicians most preferred DCIS defined as "abnormal cells in the milk ducts that had not spread to other breast tissues and which did not need urgent treatment" and least preferred the definition, "the earliest possible form of breast cancer and is non-invasive" [29].

\section{Psychosocial impact of DCIS ( $n=19$ studies)}

In some cases, women accepted their diagnosis calmly [73] and others were relieved that their disease was caught early [39]. Two studies interviewed women with DCIS and found common themes to be that it was a challenge to body integrity and identity [52] and gave a feeling of ongoing risk [39], though the possibility of reconstruction was of some comfort [52]. Women who needed a mastectomy were often very shocked and upset [46]. Women who underwent an immediate reconstruction for DCIS reported greater overall body image distress than breast-conserving surgery patients $(p=0.001)$ and marginally higher levels than those who underwent mastectomy without reconstruction $(p=0.055)$ [47]. Another study found that after treatment of DCIS, some women reported perceptions of a worsened body image (16\%), tension (46\%), nervousness (48\%), loneliness (29\%), anxiousness (59\%) and depression (41\%) [72]. Two studies found that, over time, anxiety and depression declined $[47,58]$.

Four studies examined social outcomes of DCIS diagnosis and found that women reported a high degree of social support [31,58] and women with DCIS reported less withdrawal from close family/friends (5\% vs. $11 \%, p=0.08$ ) and strain on interpersonal relationships ( $0 \%$ vs. $6 \%, p=0.02)$ compared with women with early invasive breast cancer [66]. However, one study reported that DCIS negatively affected patients' relationships with others [52].

Five studies examined the effects of DCIS on sexual function. In two studies, women with DCIS appeared to have very similar sexual function as women without DCIS [34, 51] and, in one study, women with DCIS experienced a less negative effect on their sex life compared with women with invasive breast cancer $(p=0.03)$ [64]. Half of the DCIS patients in one study reported decreased interest in sex and decreased sexual activity [70], and another $5 \%$ of patients in another study reported some limitations in sexuality, interference with sexual desire and modifications during intercourse [72].

When compared with women without breast disease, one study found that women with DCIS had statistically greater declines in quality of life [62], whereas another study found that women treated for DCIS had a similarly satisfactory quality of life [53]. Two studies found that patients with 
DCIS experienced better quality of life compared with invasive breast cancer patients [40, 64], while two other studies reported that DCIS patients and invasive breast cancer patients experienced similar levels of distress [31, 48]. Factors associated with lower quality of life were younger age, no partner and lower income [32].

\section{Interventions to support communication or decision-making ( $n=2$ studies)}

Two studies investigated interventions to facilitate DCIS communication and decision-making [27, 43]. In one study that developed a communication aid, DCIS patients and health care professionals felt that it would help women to understand their diagnosis, treatment and prognosis [43]. In another study, physicians said that they would be interested in using a web-based decision aid (http://www.onlinedecisi on.org/) that included various educational materials such as a lay language description of treatment options, outcomes data and communication support [27].

\section{Discussion}

A considerable proportion of mammographically detected lesions are DCIS, yet little research spanning 1997-2016 investigated the treatment decision-making experiences of patients or providers. Most women had little knowledge of DCIS and inaccurate perceptions of associated risks and prognosis. Physician recommendations and patient factors informed treatment decision-making and, as a result, women experienced high decisional conflict and were not satisfied with information provided to them. Many chose mastectomy, an acceptable option for women with a large area of disease or the desire to avoid radiation, or prophylactic mastectomy. Following treatment, women reported anxiety and depression, often at levels similar to those with invasive breast cancer. Disparities were identified by education level, socioeconomic status, ethnicity and literacy. Physicians agreed that patients did not understand the condition, but said that they had difficulty explaining it and many referred to it as cancer. Despite the challenges reported by patients and physicians, no studies evaluated decision aids or other policies, programmes or strategies to promote awareness, understanding and discussion about DCIS; only two studies explored patient or provider interest in communication or decision aids. Given the fact that most women with DCIS undergo extensive treatment, which is the present standard [4, 5], and many experience treatment-related clinical and psychosocial sequelae, the paucity of research on $\mathrm{PE}$ to improve and support patient-provider communication and informed decision-making for DCIS is profound.
The findings of our review also emerged in other research. For example, researchers have explored the influence of terminology on subsequent treatment decision-making. In one study of 269 women, those first exposed to the term "abnormal cells" then later "pre-invasive breast cancer cells" were more likely to feel concern and change their management preference to treatment compared to women exposed first to the term "pre-invasive breast cancer cells" and then "abnormal cells," however, there was no significant difference in treatment preferences between the two groups $(p=0.23$ ) [26]. In another study, 26 women who were interviewed said that they would feel concern regardless of the term used to describe DCIS but preferred the term abnormal cells over other terms such as carcinoma, and expressed interest in active surveillance over immediate treatment provided monitoring was very frequent [74]. Interviews with 29 early-stage breast cancer patients who underwent unilateral or contralateral prophylactic mastectomy revealed that fear translated into an overestimated risk of recurrence, contralateral breast cancer and death despite advice from surgeons [75]. Rutherford et al. reviewed the literature on treatment decision-making in DCIS [76]. While they identified themes similar to those that emerged in our study, they searched from database inception to November 2015 and included 22 articles, while we searched from database inception to February 2017 and included 51 articles; thus, our review is more current. Our review is also more comprehensive because we searched for patient or provider interventions that support communication about DCIS while Rutherford did not; consequently, a unique finding of this study was the lack of interventions aimed at patients or providers to support communication and decision-making for DCIS.

Active surveillance is a new option for managing select cancer patients to reduce potential over-treatment and the associated sequelae that can impact health and health-related quality of life [77]. It avoids or postpones definitive DCIS treatment until there is evidence from periodic observation or testing that a patient is at greater risk of or has disease progression [78]. Active surveillance has become a standard option for managing prostate cancer, and trials are currently underway to establish the clinical, molecular and psychosocial outcomes of active surveillance for DCIS [79-81]. While many are striving to improve the clinical management of DCIS, trial results are uncertain and may not be available for many years. Even if active surveillance becomes a management option for DCIS, the confusion among women caused by a diagnosis of DCIS, and the dilemma experienced by physicians in recommending treatment for a potentially benign condition remains. This review underscored the impact of DCIS on psychosocial issues and health-related quality of life, and revealed an imperative for interventions to address the needs of women diagnosed with DCIS. Engaging patients in their own care improves patient, 
provider and system-level outcomes [12-14]. A framework of person-centred cancer care stipulates the interdependence of six domains that must be addressed to provide better support to DCIS patients: fostering the patient-provider relationship, exchanging information, responding to patient emotions, managing uncertainty, making decisions and enabling patient self-management [82]. At the same time, physicians must be provided with education and tools that enable them to address these domains.

Hence, further research is needed to develop resources or tools that support communication, and informed or shared decision-making for DCIS. A Cochrane systematic review of 105 studies including 31,043 participants showed that decision aids improved knowledge, accurate risk perception and values-congruent choices when used either within or in preparation for consultation [83]. However, other research shows that awareness and use of decision aids among physicians may be limited [84, 85]. Given that, in this review, physicians influenced treatment choices but referred to DCIS as cancer and said that DCIS was challenging to describe to patients, physicians may require training to more accurately and better engage patients in discussions about DCIS. Further research is needed to understand the implementation and impact of decision aids, particularly in the context of patients who may be disadvantaged by factors such as low literacy. A range of types of tools other than decision aids can be just as effective and should also be studied in the context of DCIS. For example, print (brochures, booklets, variety of print material, list of websites) or electronic (video, computer program, website) material offered directly before, during or upon conclusion of consultations by health care professionals, health educators, researchers or volunteers improved patient knowledge, communication, decisionmaking and health care behaviour [86]. Also, increasingly patients or family members are being engaged in improving the quality of health services, often as patient navigatorsperhaps women who were treated for DCIS could function as coaches to provide supportive care for women newly diagnosed with the condition [16].

A few issues may limit the interpretation and use of these findings. Although we searched the most relevant databases of medical literature with a search that complied with standards [21], and employed rigorous searching and screening processes, we may not have identified all relevant studies. We did not search the grey literature, referring to informally published resources such as organizational reports or the content of web sites, because most empirical research would be found in indexed databases, and because there are no standards for doing so, and grey information may be at high risk of bias $[87,88]$. Publication bias, or the tendency for journals to publish studies with positive results or surveys with high response rates, may have influenced the number and type of studies that were retrieved. Given the wide range of processes and outcomes measured and reported across included studies, it was not possible to pool findings.

Despite these limitations, the purpose of this study was to assess the state of research on DCIS communication and decision-making to serve as a springboard for ongoing research in this area. In summary, this review summarized two decades of accumulated research on the challenges associated with DCIS diagnosis and management faced by women and physicians. This contrasts starkly with the absence of approaches, strategies or tools available to support communication and decision-making about DCIS, yet reveals opportunities by which the quality of care can be improved.

Funding This research was conducted with funding from the Canadian Cancer Society Research Institute.

\section{Compliance with ethical standards}

Competing interests The authors have no conflicts of interest to declare.

Open Access This article is distributed under the terms of the Creative Commons Attribution 4.0 International License (http://creativecomm ons.org/licenses/by/4.0/), which permits unrestricted use, distribution, and reproduction in any medium, provided you give appropriate credit to the original author(s) and the source, provide a link to the Creative Commons license, and indicate if changes were made.

\section{References}

1. Partridge AH, Elmore JG, Saslow D, McCaskill-Stevens W, Schnitt SJ (2012) Challenges in Ductal Carcinoma in Situ risk communication and decision-making. CA Cancer J Clin 62:203-210

2. Narod SA, Iqbal J, Giannakeas V, Sopik V, Sun P (2015) Breast cancer mortality after a diagnosis of Ductal Carcinoma In Situ. JAMA Oncol 1:888-896

3. Francis A, Thomas J, Fallowfield L et al (2015) Addressing overtreatment of screen detected DCIS; the LORIS trial. Eur J Cancer 51:2296-2303

4. The Steering Committee on Clinical Practice Guidelines for the Care and Treatment of Breast Cancer and Canadian Association of Radiation Oncologists (1998) The management of ductal carcinoma in situ (DCIS). CMAJ 158(Suppl3):S27-S34

5. Virnig BA, Tuttle TM, Shamliyan T, Kane RL (2010) Ductal Carcinoma in Situ of the breast: a systematic review of incidence, treatment and outcomes. J Natl Cancer Inst 102:170-178

6. Rathert C, Williams ES, McCaughey D, Ishqaidef G (2012) Patient perceptions of patient-centred care. Health Expect 18:199-209

7. Kennedy F, Harcourt D, Rumsey N (2009) Perceptions of ductal carcinoma in situ (DCIS) among UK health professionals. Breast 18:89-93

8. Partridge A, Winer JP, Golshan M et al (2008) Perceptions and management approaches of physicians who care for women with ductal carcinoma in situ. Clin Breast Cancer 3:275-280

9. Gagliardi AR, Légaré F, Brouwers MC, Webster F, Badley E, Straus S (2016) Patient-mediated knowledge translation (PKT) 
interventions for clinical encounters: a systematic review. Implement Sci 11:26

10. Vernooij RWM, Willson M, Gagliardi AR (2016) Characterizing patient-oriented tools that could be packaged with guidelines to promote self-management and guideline adoption: a meta-review. Implement Sci 11:52

11. Benson JR, Jatoi I, Toi M (2016) Treatment for low-risk ductal carcinoma in situ: is nothing better than something? Lancet Oncol 17:e442-e451

12. Doyle C, Lennox L, Bell D (2012) A systematic review of evidence on the links between patient experience and clinical safety and effectiveness. BMJ Open 3:e001570

13. Rathert C, Wyrwich MD, Boren SA (2013) Patient-centered care and outcomes: a systematic review of the literature. Med Care Res Rev 70:351-379

14. Stewart M, Ryan BL, Bodea C (2011) Is patient-centred care associated with lower diagnostic costs? Healthcare Policy 6:27-31

15. Dwamena F, Holmes-Rovner M, Gaulden CM et al (2012) Interventions for providers to promote a patient-centred approach in clinical consultations. Cochrane Database Syst Rev 12:CD003267

16. Carman KL, Dardess P, Maurer M, Sofaer S, Adams K, Bechtel C, Sweeney J (2013) Patient and family engagement: a framework for understanding the elements and developing interventions and policies. Health Aff 32:223-231

17. Doyle C, Lennox L, Bell D (2012) A systematic review of evidence on the links between patient experience and clinical safety and effectiveness. BMJ Open 3:e001570

18. Levac D, Colquhoun H, O'Brien KK (2010) Scoping studies: advancing the methodology. Implement Sci 5:69

19. Arksey H, O'Malley L (2005) Scoping studies: towards a methodological framework. Int J Soc Res Methodol 8:19-32

20. Moher D, Liberati A, Tetzlaff J, Altman D (2009) Preferred reporting items for systematic reviews and meta-analyses: the PRISMA statement. PLoS Med 6:e1000097

21. McGowan J, Sampson M, Salzwedel DM, Cogo E, Foerster V, Lefebvre C (2016) PRESS Peer Review of Electronic Search Strategies: 2015 guideline statement. J Clin Epidemiol 75:40-46

22. Albrecht L, Archibald M, Arseneau D, Scott SD (2013) Development of a checklist to assess the quality of reporting of knowledge translation interventions using the Workgroup for Intervention Development and Evaluation Research (WIDER) recommendations. Implement Sci 8:52

23. Janz N, Li Y, Beesley L, Wallner L, Hamilton A, Morrison R et al (2016) Worry about recurrence in a multi-ethnic population of breast cancer survivors and their partners. Support Care Cancer 24(11):4669-4678

24. Elsayegh N, Profato J, Barrera A, Lin H, Kuerer H, Ardic C et al (2015) Predictors that influence election of contralateral prophylactic mastectomy among women with Ductal Carcinoma in Situ who are BRCA-negative. J Cancer 6(7):610-615

25. Mannu G, Bettencourt-Silva J, Ahmed F, Cunnick G (2015) A nationwide cross-sectional survey of UK breast surgeons' views on the management of Ductal Carcinoma In Situ. Int J Breast Cancer 2015:1-7

26. McCaffery K, Nickel B, Moynihan R, Hersch J, Teixeira-Pinto A, Irwig $L$ et al (2015) How different terminology for ductal carcinoma in situ impacts women's concern and treatment preferences: a randomised comparison within a national community survey. BMJ Open 5(11):e008094

27. Ozanne E, Schneider K, Soeteman D, Stout N, Schrag D, Fordis $M$ et al (2015) onlineDeCISion.org: a web-based decision aid for DCIS treatment. Breast Cancer Res Treat 154(1):181-190

28. Elsayegh N, Kuerer H, Lin H, Gutierrez Barrera A, Jackson M, Muse K et al (2014) Predictors that influence contralateral prophylactic mastectomy election among women with ductal carcinoma in situ who were evaluated for BRCA genetic testing. Ann Surg Oncol 21(11):3466-3472

29. Fallowfield L, Matthews L, Francis A, Jenkins V, Rea D (2014) Low grade Ductal Carcinoma in situ (DCIS): how best to describe it? The Breast 23(5):693-696

30. López M, Kaplan C, Nápoles A, Hwang E, Livaudais J, Karliner L (2014) Satisfaction with treatment decision-making and treatment regret among Latinas and non-Latina whites with DCIS. Patient Educ Couns 94(1):83-89

31. Sanders J, Loftin A, Seda J, Ehlenbeck C (2014) Psychosocial distress affecting patients with ductal carcinoma in situ compared to patients with early invasive breast cancer. Clin J Oncol Nurs 18(6):684-688

32. Bloom J, Stewart S, Napoles A, Hwang E, Livaudais J, Karliner L et al (2013) Quality of life of Latina and Euro-American women with ductal carcinoma in situ. Psychooncology 22(5):1008-1016

33. López M, Kaplan C, Nápoles A, Livaudais J, Hwang E, Stewart $S$ et al (2013) Ductal carcinoma in situ (DCIS): posttreatment follow-up care among Latina and non-Latina White women. J Cancer Surviv 7(2):219-226

34. Bober S, Giobbie-Hurder A, Emmons K, Winer E, Partridge A (2013) Psychosexual functioning and body image following a diagnosis of ductal carcinoma in situ. J Sex Med 10(2):370-377

35. Parikh A, Kaplan C, Burke N, Livaudais-Toman J, Hwang E, Karliner L (2013) Ductal carcinoma in situ: knowledge of associated risks and prognosis among Latina and non-Latina white women. Breast Cancer Res Treat 141(2):261-268

36. Ruddy K, Meyer M, Giobbie-Hurder A, Emmons K, Weeks J, Winer E et al (2013) Long-term risk perceptions of women with ductal carcinoma in situ. Oncologist 18(4):362-368

37. Sue G, Lannin D, Au A, Narayan D, Chagpar A (2013) Factors associated with decision to pursue mastectomy and breast reconstruction for treatment of ductal carcinoma in situ of the breast. Am J Surg 206(5):682-685

38. Livaudais J, Hwang E, Karliner L, Nápoles A, Stewart S, Bloom J et al (2012) Adjuvant hormonal therapy use among women with ductal carcinoma in situ. J Womens Health 21(1):35-42

39. Kennedy F, Harcourt D, Rumsey N (2012) The shifting nature of women's experiences and perceptions of ductal carcinoma in situ. J Adv Nurs 68(4):856-867

40. Jeffe D, Pérez M, Liu Y, Collins K, Aft R, Schootman M (2012) Quality of life over time in women diagnosed with ductal carcinoma in situ, early-stage invasive breast cancer, and age-matched controls. Breast Cancer Res Treat 134(1):379-391

41. Davey C, White V, Warne C, Kitchen P, Villanueva E, Erbas B (2011) Understanding a ductal carcinoma in situ diagnosis: patient views and surgeon descriptions. Eur J Cancer Care 20(6):776-784

42. De Morgan S, Redman S, D’Este C, Rogers K (2011) Knowledge, satisfaction with information, decisional conflict and psychological morbidity amongst women diagnosed with ductal carcinoma in situ (DCIS). Patient Educ Couns 84(1):62-68

43. De Morgan S, Butow P, Lobb E, Price M, Nehill C (2011) Development and pilot testing of a communication aid to assist clinicians to communicate with women diagnosed with ductal carcinoma in situ (DCIS). Support Care Cancer 19(5):717-723

44. Kaplan C, Nápoles A, Hwang E, Bloom J, Stewart S, Nickleach D et al (2011) Selection of treatment among Latina and non-Latina white women with ductal carcinoma in situ. J Womens Health 20(2):215-223

45. Liu Y, Pérez M, Schootman M, Aft R, Gillanders W, Jeffe D (2011) Correlates of fear of cancer recurrence in women with ductal carcinoma in situ and early invasive breast cancer. Breast Cancer Res Treat 130(1):165-173

46. Prinjha S, Evans J, Ziebland S, Mcpherson A (2011) 'A mastectomy for something that wasn't even truly invasive cancer'. 
Women's understandings of having a mastectomy for screendetected Dcis: a qualitative study. J Med Screen 18(1):34-40

47. Kennedy F, Harcourt D, Rumsey N, White P (2010) The psychosocial impact of ductal carcinoma in situ (DCIS): a longitudinal prospective study. The Breast 19(5):382-387

48. Lauzier S, Maunsell E, Levesque P, Mondor M, Robert J, Robidoux A et al (2010) Psychological distress and physical health in the year after diagnosis of DCIS or invasive breast cancer. Breast Cancer Res Treat 120(3):685-691

49. Liu Y, Perez M, Aft R, Massman K, Robinson E, Myles S et al (2010) Accuracy of perceived risk of recurrence among patients with early-stage breast cancer. Cancer Epidemiol Biomarkers Prev 19(3):675-680

50. Liu Y, Pérez M, Schootman M, Aft R, Gillanders W, Ellis M et al (2010) A longitudinal study of factors associated with perceived risk of recurrence in women with ductal carcinoma in situ and early-stage invasive breast cancer. Breast Cancer Res Treat 124(3):835-844

51. Pérez M, Liu Y, Schootman M, Aft R, Schechtman K, Gillanders $\mathrm{W}$ et al (2010) Changes in sexual problems over time in women with and without early-stage breast cancer. Menopause 17(5):924-937

52. Piot-Ziegler C, Sassi M, Raffoul W, Delaloye J (2010) Mastectomy, body deconstruction, and impact on identity: a qualitative study. Br J Health Psychol 15(3):479-510

53. Sackey H, Sandelin K, Frisell J, Wickman M, Brandberg Y (2010) Ductal carcinoma in situ of the breast. Long-term follow-up of health-related quality of life, emotional reactions and body image. Eur J Surg Oncol (EJSO) 36(8):756-762

54. Schroen A, Brenin D (2010) Breast cancer treatment beliefs and influences among surgeons in areas of scientific uncertainty. Am J Surg 199(4):491-499

55. Tuttle T, Jarosek S, Habermann E, Arrington A, Abraham A, Morris T et al (2009) Increasing rates of contralateral prophylactic mastectomy among patients with ductal carcinoma in situ. J Clin Oncol 27(9):1362-1367

56. Kennedy F, Harcourt D, Rumsey N (2009) Perceptions of ductal carcinoma in situ (DCIS) among UK health professionals. The Breast 18(2):89-93

57. Kennedy F, Harcourt D, Rumsey N (2008) The challenge of being diagnosed and treated for ductal carcinoma in situ (DCIS). Eur J Oncol Nurs 12(2):103-111

58. Partridge A, Adloff K, Blood E, Dees E, Kaelin C, Golshan M et al (2008) Risk perceptions and psychosocial outcomes of women with ductal carcinoma in situ: longitudinal results from a cohort study. J Natl Cancer Inst (JNCI) 100(4):243-251

59. Partridge A, Winer J, Golshan M, Bellon J, Blood E, Dees E et al (2008) Perceptions and management approaches of physicians who care for women with ductal carcinoma in situ. Clin Breast Cancer 8(3):275-280

60. Wong S, Chen W, Bottorff J, Hislop T (2008) Treatment decision making among Chinese women with DCIS. J Psychosoc Oncol 26(4):53-73

61. Nápoles-Springer A, Livaudais J, Bloom J, Hwang S, Kaplan C (2007) Information exchange and decision making in the treatment of Latina and white women with ductal carcinoma in situ. J Psychosoc Oncol 25(4):19-36

62. Nekhlyudov L, Kroenke C, Jung I, Holmes M, Colditz G (2006) Prospective changes in quality of life after ductal carcinomain-situ: results from the Nurses' Health Study. J Clin Oncol 24(18):2822-2827

63. Prinjha S, Evans J, McPherson A (2006) Women's information needs about ductal carcinoma in situ before mammographic screening and after diagnosis: a qualitative study. J Med Screen 13(3):110-114
64. van Gestel Y, Voogd A, Vingerhoets A, Mols F, Nieuwenhuijzen G, van Driel O et al (2006) A comparison of quality of life, disease impact and risk perception in women with invasive breast cancer and ductal carcinoma in situ. Eur J Cancer 43(3):549-556

65. Katz S, Lantz P, Janz N, Fagerlin A, Schwartz K, Liu L et al (2005) Patterns and correlates of local therapy for women with ductal carcinoma-in-situ. J Clin Oncol 23(13):3001-3007

66. Rakovitch E, Franssen E, Kim J, Ackerman I, Pignol J, Paszat L et al (2003) A comparison of risk perception and psychological morbidity in women with ductal carcinoma in situ and early invasive breast cancer. Breast Cancer Res Treat 77(3):285-293

67. Shugg D, White V, Kitchen P, Pruden M, Collins J, Hill D (2002) Surgical management of ductal carcinoma in situ in Australia in 1995. ANZ J Surg 72(10):708-715

68. Staradub V, Hsieh Y, Clauson J, Langerman A, Rademaker A, Morrow M (2002) Factors that influence surgical choices in women with breast carcinoma. Cancer 95(6):1185-1190

69. De Morgan S, Redman S, White K, Cakir B, Boyages J (2002) 'Well, have I got cancer or haven't I?' The psycho-social issues for women diagnosed with ductal carcinoma in situ. Health Expect 5(4):310-318

70. Bluman L, Borstelmann N, Rimer B, Iglehart J, Winer E (2001) Knowledge, satisfaction, and perceived cancer risk among women diagnosed with ductal carcinoma in situ. J Womens Health Gend Med 10(6):589-598

71. Brown M, Koch T, Webb C (2000) Information needs of women with non-invasive breast cancer. J Clin Nurs 9(5):713-722

72. Amichetti M, Caffo O, Arcicasa M, Roncadin M, Lora O, Rigon A et al (1999) Quality of life in patients with ductal carcinoma in situ of the breast treated with conservative surgery and postoperative irradiation. Breast Cancer Res Treat 54(2):109-115

73. Webb C, Koch T (1997) Women's experiences of non-invasive breast cancer: literature review and study report. J Adv Nurs 25(3):514-525

74. Nickel B, Barratt A, Hersch J, Moynihan R, Irwig L, McCaffery $\mathrm{K}$ (2015) How different terminology for ductal carcinoma in situ (DCIS) impacts women's concern and management preferences: a qualitative study. The Breast 24(5):673-679

75. Covelli AM, Baxter NN, Fitch MI, McCready DR, Wright FC (2015) 'Taking control of cancer': understanding women's choice for mastectomy. Ann Surg Oncol 22:383-391

76. Rutherford C, Mercieca-Bebber R, Butow P, Liang WuJ, King MT (2017) Treatment decision-making in ductal carcinoma in situ: a mixed methods systematic review of women's experiences and information needs. Patient Educ Couns 100:1654-1666

77. Romero-Otero J, García-Gómez B, Duarte-Ojeda JM et al (2016) Active surveillance for prostate cancer. Int J Urol 23:211-218

78. Bruinsma S, Roobol M, Carroll P et al (2017) Expert consensus document: semantics in active surveillance for men with localized prostate cancer-results of a modified Delphi consensus procedure. Nat Rev Urol 14(5):312-322

79. Francis A, Thomas J, Fallowfield L et al (2015) Addressing overtreatment of screen detected DCIS; the LORIS trial. Eur J Cancer 51(16):2296-2303

80. Elshof LE, Tryfonidis K, Slaets L et al (2015) Feasibility of a prospective, randomised, open-label, international multicentre, phase III, non-inferiority trial to assess the safety of active surveillance for low risk ductal carcinoma in situ-the LORD study. Eur J Cancer 51(12):1497-1510

81. Comparison of operative versus medical endocrine therapy for low risk DCIS: the COMET Trial. PCORI. (2017) http://www.pcor i.org/research-results/2016/comparison-operative-versus-medi cal-endocrine-therapy-low-risk-dcis-comet. Accessed 6 Sept 2017 
82. McCormack LA, Treiman K, Rupert D, Williams-Piehota P, Nadler E, Arora NK, Lawrence W, Street RL Jr (2011) Measuring patient-centered communication in cancer care: a literature review and the development of a systematic approach. Soc Sci Med 72:1085-1095

83. Stacey D, Légaré F, Lewis K et al (2017) Decision aids for people facing health treatment or screening decisions. Cochrane Database Syst Rev 4:1-297

84. Brace C, Schmocker S, Huang H, Victor JC, McLeod RS, Kennedy ED (2010) Physicians' awareness and attitudes toward decision aids for patients with cancer. J Clin Oncol 28:2286-2292

85. O'Brien MA, Charles C, Lovrics P et al (2014) Enablers and barriers to using patient decision aids in early stage breast cancer consultations: a qualitative study of surgeons' views. Implement Sci 9:174

86. Gagliardi A, Légaré F, Brouwers M, Webster F, Badley E, Straus S (2015) Patient-mediated knowledge translation (PKT) interventions for clinical encounters: a systematic review. Implement Sci $11: 26$

87. Benzies KM, Premii S, Hayden KA, Serrrett K (2006) State-ofthe-evidence reviews: advantages and challenges of including grey literature. Worldviews Evidence Nurs 3:55-61

88. Adams J, Hillier-Brown FC, Moore HJ, Lake AA, Araujo-Soares V, White M, Summerbell C (2016) Searching and synthesizing 'grey literature' and 'grey information' in public health: critical reflections on three case studies. Syst Rev 5:164

\section{Affiliations}

\section{Claire Kim ${ }^{1}$ - Laurel Liang ${ }^{1} \cdot$ Frances C. Wright ${ }^{2}$ - Nicole J. Look Hong ${ }^{2}$. Gary Groot ${ }^{3} \cdot$ Lucy Helyer $^{4}$ - Pamela Meiers ${ }^{3}$. May Lynn Quan ${ }^{5} \cdot$ Robin Urquhart $^{4} \cdot$ Rebecca Warburton $^{6} \cdot$ Anna R. Gagliardi $^{1}$ (I)}

Claire Kim

claire.kim@uhnresearch.ca

Laurel Liang

laurel.liang@uhnresearch.ca

Frances C. Wright

frances.wright@sunnybrook.ca

Nicole J. Look Hong

nicole.lookhong@sunnybrook.ca

Gary Groot

gary.groot@gmail.com

Lucy Helyer

lucy.helyer@nshealth.ca

Pamela Meiers

pjm121@mail.usask.ca
May Lynn Quan

mquan@ucalgary.ca

Robin Urquhart

robin.urquhart@nshealth.ca

Rebecca Warburton

rwarburton@providencehealth.bc.ca

University Health Network, Toronto, Canada

2 Sunnybrook Health Sciences Centre, Toronto, Canada

3 University of Saskatchewan, Saskatoon, Canada

4 Dalhousie University, Halifax, Canada

5 University of Calgary, Calgary, Canada

6 University of British Columbia, Vancouver, Canada 